\title{
Inhaled corticosteroids and risk of lung cancer among chronic obstructive pulmonary disease patients: a comprehensive analysis of nine prospective cohorts
}

\author{
Fan Ge ${ }^{1,2 \#}$, Yi Feng ${ }^{1,3 \#}$, Zhenyu Huo ${ }^{1,3 \#}$, Caichen Li $^{1 \#}$, Runchen Wang ${ }^{1,3}$, Yaokai Wen ${ }^{1,3}$, Sirui Gao ${ }^{1,3}$, \\ Haoxin Peng ${ }^{1,3}$, Xiangrong $W^{1,3}$, Hengrui Liang ${ }^{1}$, Bo Cheng ${ }^{1}$, Ran Zhong ${ }^{1}$, Jianxing He ${ }^{1}$, Wenhua Liang ${ }^{1}$ \\ ${ }^{1}$ Department of Thoracic Surgery and Oncology, China State Key Laboratory of Respiratory Disease \& National Clinical Research Center for \\ Respiratory Disease, the First Affiliated Hospital of Guangzhou Medical University, Guangzhou, China; ${ }^{2}$ First Clinical School, Guangzhou Medical \\ University, Guangzhou, China; ${ }^{3}$ Nanshan School, Guangzhou Medical University, Guangzhou, China \\ Contributions: (I) Conception and design: J He, W Liang, C Li, Y Wen, H Liang; (II) Administrative support: J He, W Liang; (III) Provision of study \\ materials or patients: None; (IV) Collection and assembly of data: F Ge, Y Feng, Z Huo, C Li, R Wang, Y Wen, H Peng, R Zhong, S Gao, X Wu; (V) \\ Data analysis and interpretation: F Ge, Y Feng, Z Huo, C Li, R Wang, S Gao, B Cheng, R Zhong; (VI) Manuscript writing: All authors; (VII) Final \\ approval of manuscript: All authors. \\ \#These authors contributed equally to this work. \\ Correspondence to: Jianxing He; Wenhua Liang. Department of Thoracic Surgery and Oncology, The First Affiliated Hospital of Guangzhou Medical \\ University; State Key Laboratory of Respiratory Disease \& National Clinical Research Center for Respiratory Disease; Guangzhou Institute of \\ Respiratory Health, Guangzhou 510120, China. Email: drjianxing.he@gmail.com; liangwh1987@163.com.
}

Background: It remains uncertain whether there is a protective effect of inhaled corticosteroids (ICs) against lung cancer in chronic obstructive pulmonary disease (COPD) patients.

Methods: Databases including PubMed, Web of Science, EMBASE, and Medline were comprehensively searched. Random-effects model meta-analysis was conducted to calculate the hazard ratios (HRs) for lung cancer incidence among ICs users versus non-ICs users in patients with COPD. Stratified analysis was performed based on region and age of each study. This review was registered on PROSPERO (registration number CRD42020159082).

Results: Based on data from 181,859 COPD patients with a total follow-up duration of 1,109,339.9 person-years, we identified that the use of ICs in COPD patients was associated with a decreased risk of lung cancer [HR: 0.73, 95\% confidence interval (CI): 0.62-0.86; $\mathrm{P}<0.001$ ]. The region-specific HRs for lung cancer incidence were 0.62 (95\% CI: 0.62-0.86; P=0.004), 0.77 (95\% CI: 0.60-0.97; P=0.028) and 0.81 (95\% CI: 0.61-1.08; P=0.155) among European, Asian and North American COPD patients, respectively. Additionally, we found the consistent outcome among age groups ( $\geq 70$ years old: HR: 0.73 , 95\% CI: $0.65-$ 0.99, $\mathrm{P}=0.043$; <70 years old: HR: 0.74, 95\% CI: 0.56-0.99, $\mathrm{P}=0.040)$.

Conclusions: This study demonstrates that ICs have a protective effect against lung cancer in COPD patients. It could provide guidance for clinicians in the prevention of lung cancer among patients with COPD.

Keywords: Inhaled corticosteroids; chronic obstructive pulmonary disease; lung cancer; meta-analysis

Submitted Oct 18, 2020. Accepted for publication Jan 03, 2021.

doi: $10.21037 /$ tlcr-20-1126

View this article at: http://dx.doi.org/10.21037/tlcr-20-1126 


\section{Introduction}

With a prevalence of $10.2 \%$ among people more than 40 years old around the world, chronic obstructive pulmonary disease (COPD) seems to be a rather prevalent respiratory disease (1). COPD is a disease with insidious onsets and a poor prognosis. More than $70 \%$ COPD patients are at stage 1 or 2 of Global Initiative for Chronic Obstructive Lung Disease (GOLD), with very mild respiratory symptoms such as Shortness of Breath on Exertion (SOBOE). As a result, few of them would seek medical consultations before acute exacerbation $(2,3)$.

COPD is an inflammatory disease of the respiratory system and is considered as a risky element of lung cancer (4). A comprehensive review of studies reported some possible pathogenic mechanisms to explain the potential association between COPD and lung cancer (5). Other literature suggested that the severity of COPD was positively correlated with the development of lung cancer $(6,7)$. Inflammation is also associated with lung cancer. Some studies found that chronic inflammation was involved at the onset of lung cancer through some mechanisms, which were partially independent of smoking $(8,9)$. Therefore, it is reasonable to carry out some research on early anti-inflammatory therapy in COPD patients to prevent malignant transformation.

Some cohort studies showed that inhaled corticosteroids (ICs) may delay or prevent the incidence of lung cancer to some extent (10-12). Nevertheless, some cohort studies showed that compared with general population, COPD patients using ICs demonstrated an increased risk of lung cancer $(13,14)$. Therefore, the protective effect of ICs for lung cancer in COPD patients was not clear. We performed a systematic review including a meta-analysis to determine the exact effect of ICs of lung cancer in COPD patients. We present the following article in accordance with the Preferred Reporting Items for Systematic Reviews and Meta-Analyses (PRISMA) reporting checklist (available at: http://dx.doi.org/10.21037/tlcr-20-1126).

\section{Methods}

\section{Systematic review}

PubMed (update to February 2020), EMBASE (from 1980 to February 2020), Web of Science (update to February 2020), and Medline (from 1966 to February 2020) were comprehensively searched to identify longitudinal epidemiological studies. We amalgamated "inhaled corticosteroids" or "ICs" or "chronic obstructive pulmonary disease" or "COPD" with "lung cancer", "neoplasm" and "tumor", along with their Medical Subject Headings (MeSH) terms. In addition, we conducted manual searches of the reference lists originating from materials published in academic conferences and retrieved review articles. We would contact the corresponding authors for supplementary data when important information was missing. All searched results were evaluated according to the PRISMA statement (15). Protocol of this study was registered in the Prospective Register of Systematic Reviews (PROSPERO CRD42020159082).

\section{Study selection criteria}

Eligible studies were selected according to the following inclusion criteria: (I) designed on the basis of populationbased cohort studies of COPD patients; (II) reported the risk of lung cancer in COPD patients taking ICs; (III) crude hazard ratios (HRs) or adjusted HRs ratios and $95 \%$ confidence intervals (CIs) could be obtained or directly estimated from the article. Studies met any of the criteria below would be excluded: (I) COPD patients reported to have developed any type of cancer before using ICs; (II) lack of available data with appropriate statistics, such as study only reported the risk of lung cancer in COPD patients who used different doses of ICs and did not report the overall risk of lung cancer in COPD patients using ICs; (III) case series and case reports; (IV) not written in English.

\section{Data extraction and quality assessment}

Three authors (FG, ZH, YF) extracted the data independently and any divergence resolved by consensus. Following information was recorded: the first author's name, country, study period and publication year, sources of COPD patients, number of COPD patients taking ICs, number of COPD patients not taking ICs, median followup duration (years), mean or median age of COPD patients (years), crude HRs or adjusted HRs with 95\% CIs, and the confounders that the HRs has adjusted.

The Newcastle Ottawa Scale (NOS) was used to evaluate the methodological quality of the selected studies (16) (Table 1), including selection (4 items), comparability (1 item), and outcome (3 items). Any disagreement was 
Table 1 Demographic details of the included studies

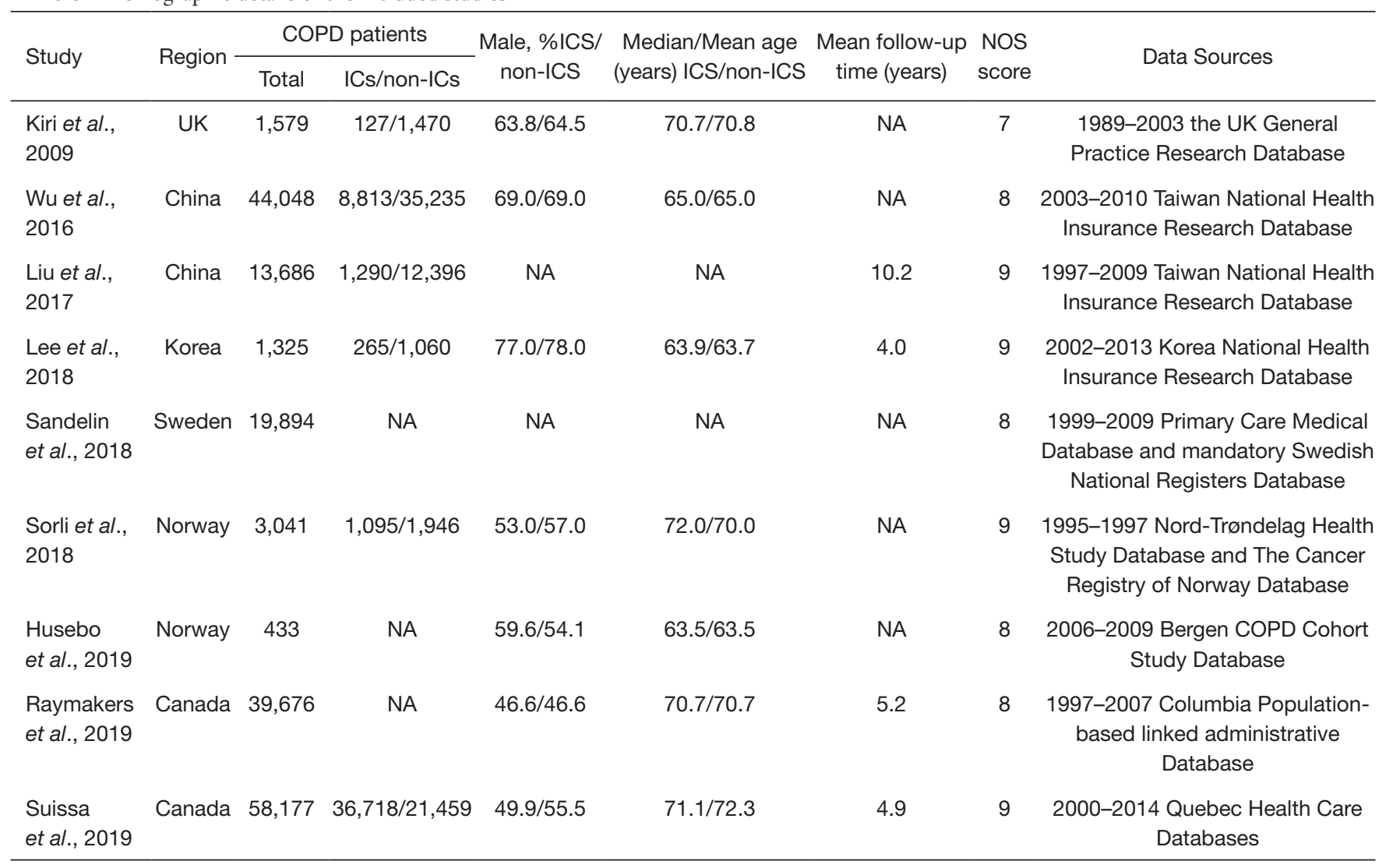

COPD, chronic obstructive pulmonary disease; ICs, inhaled corticosteroids.

resolved by consensus.

\section{Statistical analysis}

Dichotomous data were extracted using crude HRs or adjusted HRs with $95 \%$ CIs. We restricted analyses to studies that adjusted for at least three of the following known confounders: age, gender, body mass index, smoking situation, socioeconomic status, and comorbidities. Adjusted HRs were used in preference wherever available. To avoid the potential heterogeneity existed between studies, we used random-effects model to synthesize HRs and $95 \%$ CIs for ICs users versus non-ICs users to determine the risk of lung cancer. Cochran's Q test and the $\mathrm{I}^{2}$ statistic were used to assess the heterogeneity. Significant heterogeneity was considered in pooled statistics when $\mathrm{P}$-value $\leq 0.05$ and $\mathrm{I}^{2}$ statistic $\geq 50 \%$. Stratified analysis based on patients' age (70 years or older, $<70$ years) and region (Europe, Asia, North America) were carried out. Additionally, we performed sensitivity analyses after the sequential removal of each study. Publication bias was evaluated by conducting Begg's test and Egger's test, and significant publication bias was set as $P$ value $<0.05$. All analyses were conducted using STATA 15.0 software (STATA Corp, College Station, TX, USA). All the $\mathrm{P}$ values were 2-tailed; statistical significance was set as $\mathrm{P}$ value $<0.05$.

\section{Results}

\section{Study selection}

Our search identified 816 potentially eligible published studies. 225 of them were excluded after screening the title and abstract. 45 articles were excluded because the data were not displayed in a suitable format for synthesis. Finally, 9 studies (11-14,17-21) met the inclusion criteria and were included in the meta-analysis (Figure 1).

\section{Study characteristics}

All 9 studies were prospective cohorts from different 

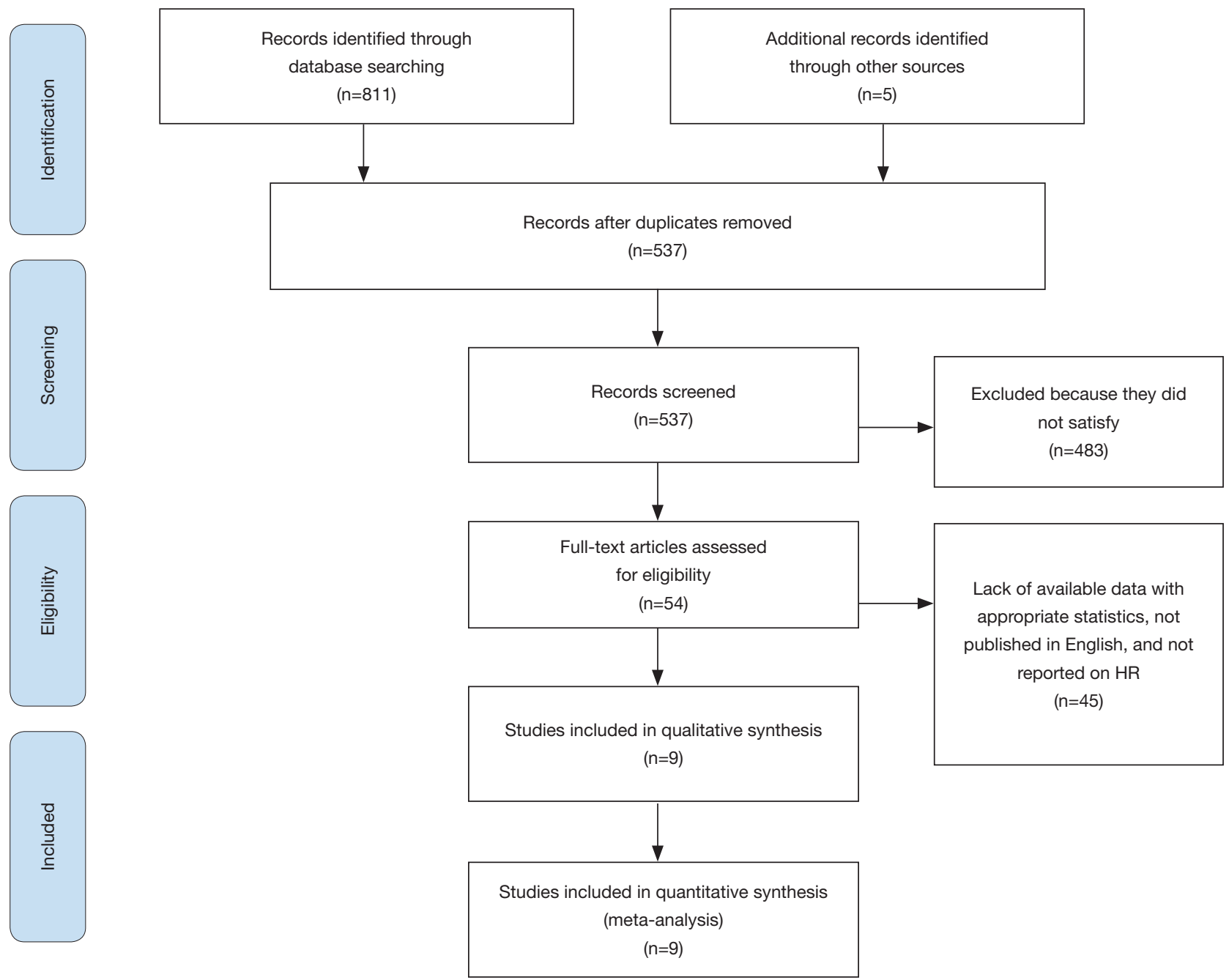

Figure 1 PRISMA diagram of study selection.

countries, including one in UK (11), two in China $(17,18)$, one in South Korea (19), one in Sweden (20), two in Norway $(12,14)$, and two in Canada $(13,21)$. Demographic details of the included studies and the data source of included COPD patients is shown in Table 1. Of noted, the included 181,859 COPD patients were followed up for a total of 1,109,339.9 person-years, with a mean follow-up duration of 6.1 years (range, $4.0-10.2$ years). The mean age was 68.1 (range, 63.5-71.1) and 68.0 (range, 63.5-72.3) in patients with and without the use of ICs, respectively.

\section{Risk of lung cancer in ICs users}

A pooled analysis of 9 studies found that ICs have a protective effect against lung cancer in COPD patients (HR: 0.73 , 95\% CI: $0.62-0.86 ; \mathrm{P}<0.001$ ). Figure 2 shows the individual and overall HR measures.

Remarkable heterogeneity existed $\left(\mathrm{I}^{2}=64.4 \%\right.$, $\left.\mathrm{P}_{\text {heterogeneity }}=0.004\right)$ in the pooled analysis. When stratified by patients age, the HRs for lung cancer were 0.80 (95\% CI: $0.65-0.99, \mathrm{P}=0.043, \mathrm{I}^{2}=71.7 \%, \mathrm{P}_{\text {heterogeneity }}=0.014$ ) for patients aged 70 or above and 0.73 (95\% CI: 0.54-0.99, $\left.\mathrm{P}=0.040, \mathrm{I}^{2}=49.6 \%, \mathrm{P}_{\text {heterogeneity }}=0.137\right)$ for patients who were younger than 70 (Figure 3). Additionally, stratification analyses of different regions showed that the HRs for lung cancer were 0.62 (95\% CI: $0.45-0.86, \mathrm{P}=0.004, \mathrm{I}^{2}=49.5 \%$, $\left.\mathrm{P}_{\text {heterogeneity }}=0.114\right)$ for European patients and 0.77 (95\% CI: $0.60-0.97, \mathrm{P}=0.028, \mathrm{I}^{2}=32.5 \%, \mathrm{P}_{\text {heterogeneity }}=0.228$ ) for Asian 


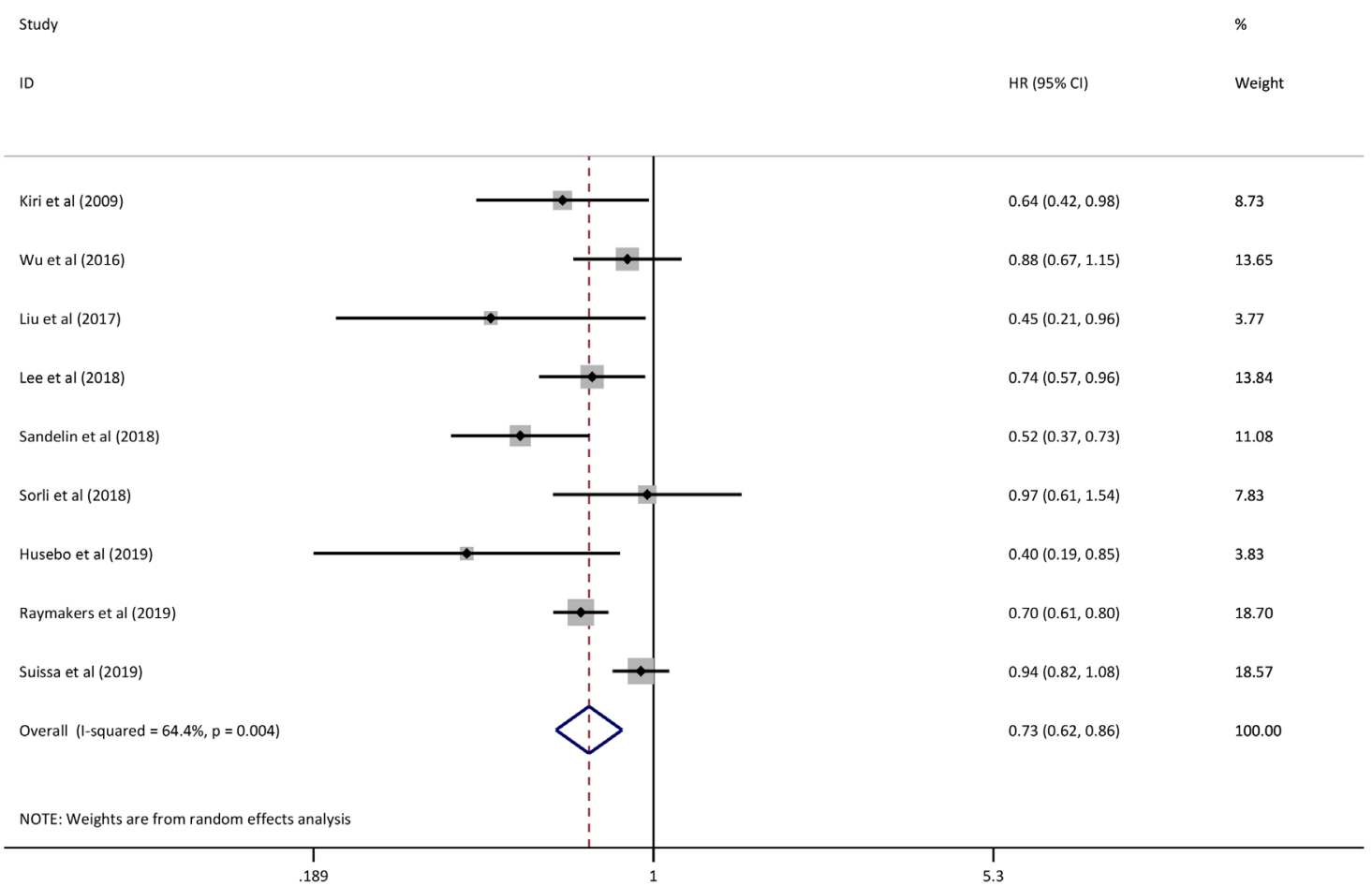

Figure 2 Forest plot of lung cancer risk, showing the hazard ratios (HRs) and 95\% confidence intervals (CIs). The squares and horizontal lines correspond to the study-specific HR and $95 \%$ CI. The area of the squares reflects the study-specific weight.

patients (Figure 4).

\section{Sensitivity analysis and publication bias}

Sensitivity analysis showed that the removal of any of the studies do not influence the results (Table 2). It is worth mentioning that when the study of Suissa (13) was removed, the heterogeneity was eliminated but the result was stable (HR: $0.70,95 \%$ CI: $0.60-0.81 ; \mathrm{P}<0.001$ ), suggesting that the study could be the potential source of inter-study variability. Furthermore, results of Egger's test $(\mathrm{P}=0.191)$ or Begg's test $(\mathrm{P}=0.602$, Figure 5) showed no evidence of publication bias for lung cancer analyzed in COPD patients.

\section{Discussion}

Our study was aiming at exploring whether ICs have a protective effect against lung cancer in COPD patients. We found that ICs were associated with a decreased risk of lung cancer in patients with COPD and the outcome was consistent among different age groups and region groups.

A previous meta-analysis has shown that ICs reduced neutrophil and lymphocyte counts in bronchoalveolar lavage fluid from patients with COPD, which suggested that the use of ICs could decrease airway inflammation (22). Therefore, the immunomodulatory effect of ICs on the airways of COPD patients may play an important role in reducing the risk of lung cancer. In recent years, basic studies indicated that COPD may possibly triggered through initial epithelial activation. As the first line defense for external invasion, the epithelial cells act as a barrier to infectious organisms and toxic particles produced from entities (23). Moreover, epithelial cells also produce various antioxidant, antibacterial, anti-protease factors and have tight junctions which could deny any entry of foreign entities and prevent them from damaging or destroying the inner lung mucosa $(24,25)$. In COPD patients, the phlegm-thickened mucus, impaired ciliary function, and chronic exposure to external invasions may cause observable changes to the normal structures of the epithelium (26), which called epithelialmesenchymal transition (EMT) (27). EMT is a process by which epithelial cells progressively lose cellular polarity and adhesiveness, thus become migratory and assume a mesenchymal phenotype (28-30). The characteristics of 


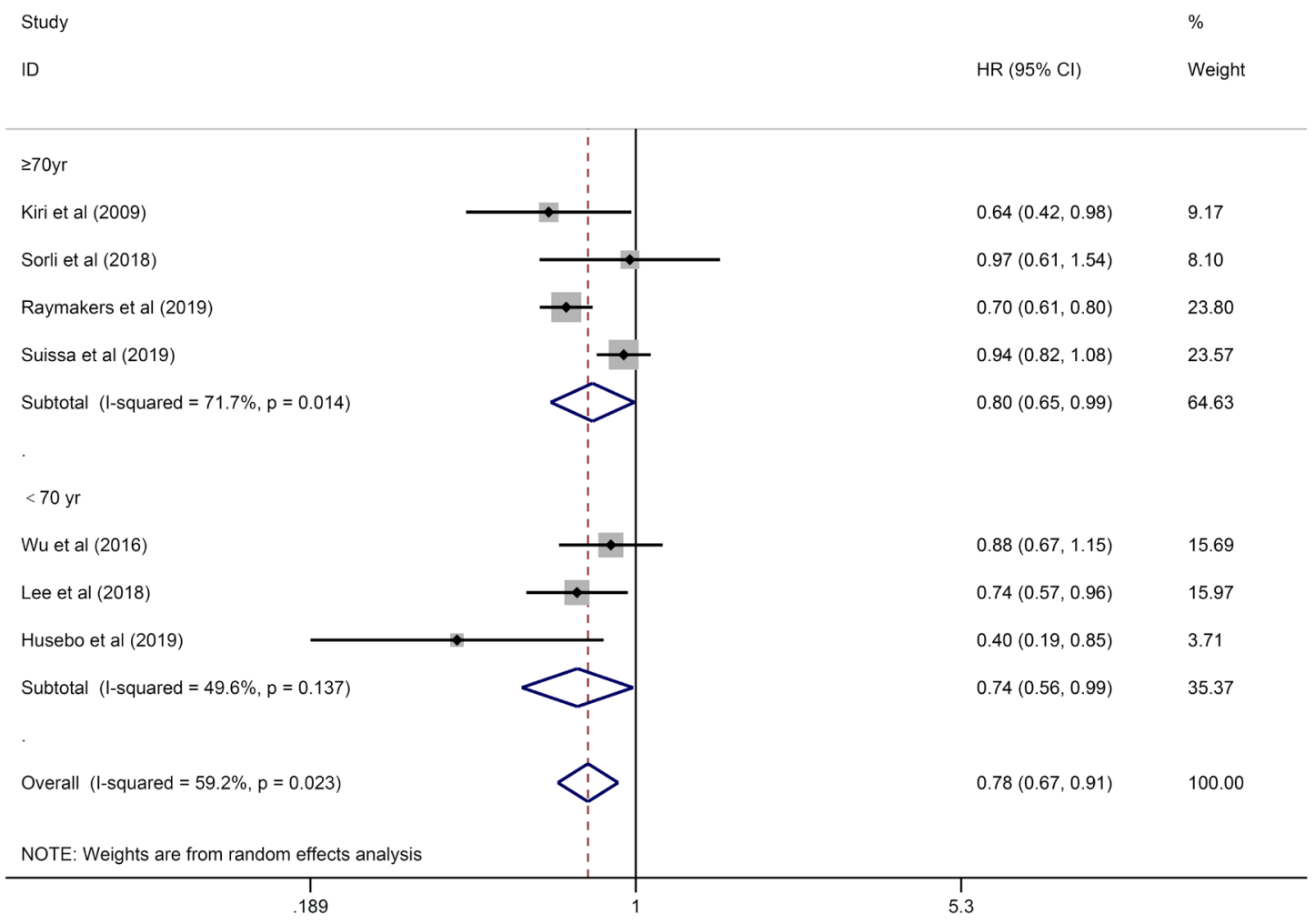

Figure 3 Forest plot of lung cancer risk stratified by age.

EMT are as follows: (I) increased cellular expression of mesenchymal biomarkers such as vimentin and S100A4 (31), which is higher in basal cells especially $(32,33)$; (II) reticular basement membrane $(\mathrm{Rbm})$ fragmentation owing to epithelial matrix metalloprotease (MMP) activity, especially the increase of MMP-9 (collagenase/gelatinase) (31). Additionally, as the prominent feature of EMT, increased $\mathrm{Rbm}$ could lead to the formation of a pro-cancer stroma (34). More and more evidence (35-37) has shown that EMT may lead to the elevated risk of lung cancer in patients with COPD. Indeed, epithelia with active EMT are potentially delicate to malignant transformation (38), and EMT in airways of COPD patients may well be the vital bridge between airway fibrosis and cancer development (39). Furthermore, Mahmood et al. (40) found that there were strong correlations between the activity of EMT in the leading edge of invasive malignancies and the activity of EMT in the nonmalignant airway areas from which the neoplasm originated. On the other hand, ICs protective effect on lung cancer in COPD patients may also be linked to EMT. Recently, Sohal et al. (41) showed that ICs were effective in decreasing mesenchymal expression of vimentin and S100A4, along with significant reduction in Rbm fragmentation, EGFR and MMP-9 expression in COPD patients. This trial indicated strong suggestive support for ICs' an anti-EMT effect in airways of COPD patients, which may also clarify the links between ICs use and the protection effect against lung cancer in COPD patients.

It is worth mentioning that a dose-response relationship between ICs exposure and lung cancer risk was observed by two studies $(10,11)$, which showed that higher ICs doses were associated with a lower risk of lung cancer. We also noted that it was not a random decision to use ICs or not. ICs would be recommended to those COPD patients who had experienced lots of episodes of acute exacerbation or had forced expiratory volume in 1 second (FEV1) $<50 \%$ (42). According to recommendations, patients with more severe inflammation or lower FEV1 should consider using ICs. However, lung cancer has been known to be inflammationassociated (43) and related to reduced FEV1 (44). Therefore, although ICs might be in the prescription of patients with high lung cancer risk, lower lung cancer risk was observed in ICs users than non-users in our study, suggesting that ICs had multiple effects in preventing lung 


Study
ID

Figure 4 Forest plot of lung cancer risk stratified by region.

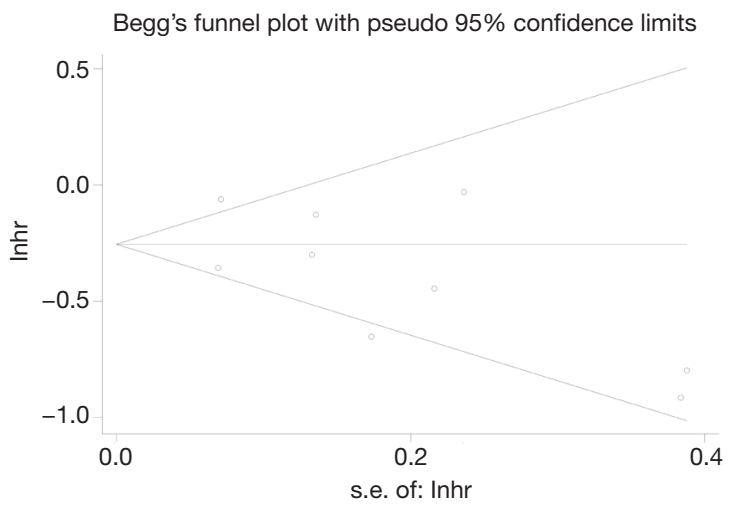

Figure 5 Begg's funnel plot to detect publication bias in overall populations. Each circle represents a separate study for the indicated association.

cancer. Recently, corticosteroids such as budesonide and dexamethasone have been shown to have an inhibitory effect of the proliferation of A549 cells, which is a glucocorticoidreceptor (GR)-rich adenocarcinoma-derived human alveolar epithelial cell line (45). Corticosteroids were thought to inhibit the retinoblastoma $(\mathrm{Rb})$ phosphorylation to prevent progression from $G_{1}$ phase to $S$ phase (45). Another in vitro study, Liang (46). showed that the anti-proliferative effect of corticosteroids required functional $\mathrm{p} 53$, which plays an essential role in liganded GR repression the NF- $\kappa \mathrm{B}$ pathway (47). The NF-кB pathway is constitutively active in most malignancies (48). These studies mainly showed that ICs have an inhibitory effect on GR-rich non-small cell lung cancer (NSCLC) cell lines, which may explain the decreased risk of lung cancer in COPD patients receiving ICs. Furthermore, in mouse models, corticosteroids have been shown to modulate proto-oncogene expression and produce $70 \%$ inhibition of lung tumor multiplicity (49).

Three strengths of this study should be highlighted. First, to the best of our knowledge, this is the first metaanalysis to analyze whether the use of ICs in patients with COPD reduces the risk of lung cancer. Second, the included study sample was large and the follow-up time was long enough, hence reducing the likelihood of selection biases. Third, a stratified analysis was performed based on patients' age and region to explore if there were age-based 
Table 2 Sensitivity analysis

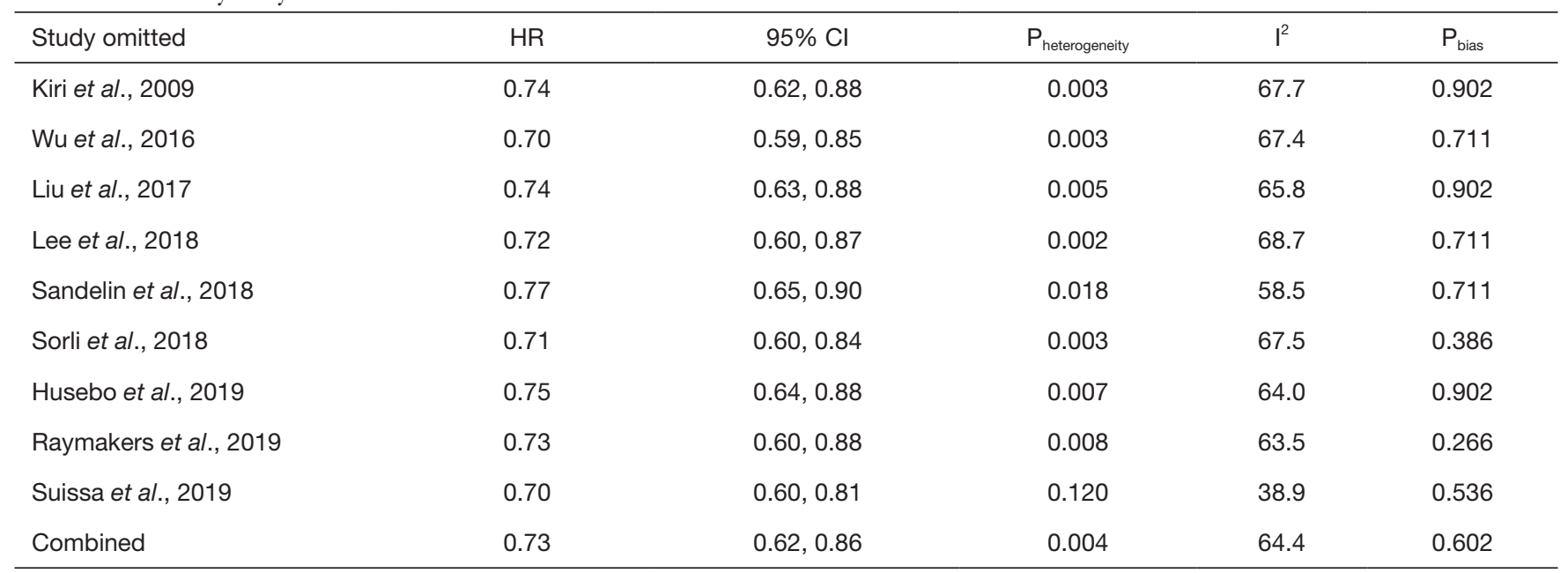

$\mathrm{HR}$, hazard ratio; $\mathrm{Cl}$, confidence intervals.

and region-based differences.

We acknowledged some limitations in regards to our meta-analysis. First, because of the different methods used to describe the dose-response of ICs in the included studies, we were unable to combine them to determine if there was a dose-response relationship. Second, the included studies did not contain detailed information regarding smoking status (50), drug use (51), sex (52) and occupational exposures (53), all of which might be risk factors for lung cancer and could not be analyzed in this study. Third, due to data limitations, we were unable to collect and analyze the data of different subtypes of lung cancer to explore the influence of tumor properties on the lung cancer risk of COPD patients. Fourth, due to the inclusion of research publications, publication bias was inevitable.

In conclusion, this meta-analysis demonstrates that ICs have a protective effect against lung cancer in COPD patients. Such an association can provide guidance for clinicians in the prevention of lung cancer among patients with COPD.

\section{Acknowledgments}

Funding: This study was supported by the National Natural Science Foundation of China (Grant No.81871893) and Key Project of Guangzhou Scientific Research Project
(Grant No.201804020030) provide and maintain database.

\section{Footnote}

Reporting Checklist: The authors have completed the PRISMA reporting checklist. Available at: http://dx.doi.org/10.21037/ tlcr-20-1126

Conflicts of Interest: All authors have completed the ICMJE uniform disclosure form (available at: http://dx.doi. org/10.21037/tlcr-20-1126). The authors have no conflicts of interest to declare.

Ethical Statement: The authors are accountable for all aspects of the work in ensuring that questions related to the accuracy or integrity of any part of the work are appropriately investigated and resolved.

Open Access Statement: This is an Open Access article distributed in accordance with the Creative Commons Attribution-NonCommercial-NoDerivs 4.0 International License (CC BY-NC-ND 4.0), which permits the noncommercial replication and distribution of the article with the strict proviso that no changes or edits are made and the original work is properly cited (including links to both the formal publication through the relevant DOI and the license). 
See: https://creativecommons.org/licenses/by-nc-nd/4.0/.

\section{References}

1. Buist AS, McBurnie MA, Vollmer WM, et al. International variation in the prevalence of COPD (the BOLD Study): a population-based prevalence study. Lancet 2007;370:741-50.

2. Zhong N, Wang C, Yao W, et al. Prevalence of chronic obstructive pulmonary disease in China: a large, population-based survey. Am J Respir Crit Care Med 2007;176:753-60.

3. Zhou Y, Zhong N-S, Li X, et al. Tiotropium in EarlyStage Chronic Obstructive Pulmonary Disease. N Engl J Med 2017;377:923-35.

4. Hong Q-Y, Wu G-M, Qian G-S, et al. Prevention and management of lung cancer in China. Cancer 2015;121 Suppl 17:3080-8.

5. Brody JS, Spira A. State of the art. Chronic obstructive pulmonary disease, inflammation, and lung cancer. Proc Am Thorac Soc 2006;3:535-7.

6. Skillrud DM, Offord KP, Miller RD. Higher risk of lung cancer in chronic obstructive pulmonary disease. A prospective, matched, controlled study. Ann Intern Med 1986;105:503-7.

7. Young RP, Hopkins RJ, Christmas T, et al. COPD prevalence is increased in lung cancer, independent of age, sex and smoking history. Eur Respir J 2009;34:380-6.

8. Ardies CM. Inflammation as cause for scar cancers of the lung. Integr Cancer Ther 2003;2:238-46.

9. Turner MC, Chen Y, Krewski D, et al. Chronic obstructive pulmonary disease is associated with lung cancer mortality in a prospective study of never smokers. Am J Respir Crit Care Med 2007;176:285-90.

10. Parimon T, Chien JW, Bryson CL, et al. Inhaled corticosteroids and risk of lung cancer among patients with chronic obstructive pulmonary disease. Am J Respir Crit Care Med 2007;175:712-9.

11. Kiri VA, Fabbri LM, Davis KJ, et al. Inhaled corticosteroids and risk of lung cancer among COPD patients who quit smoking. Respir Med 2009;103:85-90.

12. Husebo GR, Nielsen R, Hardie J, et al. Risk factors for lung cancer in COPD - results from the Bergen COPD cohort study. Respir Med 2019;152:81-8.

13. Suissa S, Dell'Aniello S, Gonzalez AV, et al. Inhaled corticosteroid use and the incidence of lung cancer in COPD. Eur Respir J 2020;55:1901720.
14. Sorli K, Thorvaldsen SM, Hatlen P. Use of Inhaled Corticosteroids and the Risk of Lung Cancer, the HUNT Study. Lung 2018;196:179-84.

15. Moher D, Liberati A, Tetzlaff J, et al. Preferred reporting items for systematic reviews and meta-analyses: the PRISMA statement. BMJ 2009;339:b2535.

16. Stang A. Critical evaluation of the Newcastle-Ottawa scale for the assessment of the quality of nonrandomized studies in meta-analyses. Eur J Epidemiol 2010;25:603-5.

17. Wu MF, Jian ZH, Huang JY, et al. Post-inhaled corticosteroid pulmonary tuberculosis and pneumonia increases lung cancer in patients with COPD. BMC Cancer 2016;16:778.

18. Liu SF, Kuo HC, Lin MC, et al. Inhaled corticosteroids have a protective effect against lung cancer in female patients with chronic obstructive pulmonary disease: a nationwide population-based cohort study. Oncotarget 2017;8:29711-21.

19. Lee YM, Kim SJ, Lee JH, et al. Inhaled corticosteroids in COPD and the risk of lung cancer. Int J Cancer 2018;143:2311-8.

20. Sandelin M, Mindus S, Thuresson M, et al. Factors associated with lung cancer in COPD patients. Int J Chron Obstruct Pulmon Dis 2018;13:1833-9.

21. Raymakers AJ, Sadatsafavi M, Sin DD, et al. Inhaled corticosteroids and the risk of lung cancer in COPD: a population-based cohort study. Eur Respir J 2019;53:1801257.

22. Jen R, Rennard SI, Sin DD. Effects of inhaled corticosteroids on airway inflammation in chronic obstructive pulmonary disease: a systematic review and meta-analysis. Int J Chron Obstruct Pulmon Dis 2012;7:587-95.

23. Hallstrand TS, Hackett TL, Altemeier WA, et al. Airway epithelial regulation of pulmonary immune homeostasis and inflammation. Clin Immunol 2014;151:1-15.

24. Moheimani F, Roth HM, Cross J, et al. Disruption of $\beta$-catenin/CBP signaling inhibits human airway epithelialmesenchymal transition and repair. Int J Biochem Cell Biol 2015;68:59-69.

25. Puchelle E, Zahm JM, Tournier JM, et al. Airway epithelial repair, regeneration, and remodeling after injury in chronic obstructive pulmonary disease. Proc Am Thorac Soc 2006;3:726-33.

26. Aghapour M, Raee P, Moghaddam SJ, et al. Airway Epithelial Barrier Dysfunction in Chronic Obstructive Pulmonary Disease: Role of Cigarette Smoke Exposure. 
Am J Respir Cell Mol Biol 2018;58:157-69.

27. Sohal SS. Airway Basal Cell Reprogramming and Epithelial-Mesenchymal Transition: A Potential Key to Understanding Early Chronic Obstructive Pulmonary Disease. Am J Respir Crit Care Med 2018;197:1644-5.

28. Nowrin K, Sohal SS, Peterson G, et al. Epithelialmesenchymal transition as a fundamental underlying pathogenic process in COPD airways: fibrosis, remodeling and cancer. Expert Rev Respir Med 2014;8:547-59.

29. Sohal SS. Endothelial to mesenchymal transition (EndMT): an active process in Chronic Obstructive Pulmonary Disease (COPD)? Respir Res 2016;17:20.

30. Königshoff $M$. Lung cancer in pulmonary fibrosis: tales of epithelial cell plasticity. Respiration 2011;81:353-8.

31. Sohal SS, Reid D, Soltani A, et al. Reticular basement membrane fragmentation and potential epithelial mesenchymal transition is exaggerated in the airways of smokers with chronic obstructive pulmonary disease. Respirology 2010;15:930-8.

32. Mahmood MQ, Sohal SS, Shukla SD, et al. Epithelial mesenchymal transition in smokers: large versus small airways and relation to airflow obstruction. Int J Chron Obstruct Pulmon Dis 2015;10:1515-24.

33. Schneider M, Hansen JL, Sheikh SP. S100A4: a common mediator of epithelial-mesenchymal transition, fibrosis and regeneration in diseases? J Mol Med (Berl) 2008;86:507-22.

34. Soltani A, Walters EH, Reid DW, et al. Inhaled corticosteroid normalizes some but not all airway vascular remodeling in COPD. Int J Chron Obstruct Pulmon Dis 2016;11:2359-67.

35. Jolly MK, Ward C, Eapen MS, et al. Epithelialmesenchymal transition, a spectrum of states: Role in lung development, homeostasis, and disease. Dev Dyn 2018;247:346-58.

36. Sohal SS, Walters EH. Advanced Non-Small-Cell Lung Cancer. N Engl J Med 2017;377:1998-9.

37. Gurzu S, Turdean S, Kovecsi A, et al. Epithelialmesenchymal, mesenchymal-epithelial, and endothelialmesenchymal transitions in malignant tumors: An update. World J Clin Cases 2015;3:393-404.

38. Sohal SS, Hansbro PM, Walters EH. Epithelial Mesenchymal Transition in Chronic Obstructive Pulmonary Disease, a Precursor for Epithelial Cancers: Understanding and Translation to Early Therapy. Ann Am Thorac Soc 2017;14:1491-2.

39. Sohal SS. Chronic Obstructive Pulmonary Disease
(COPD) and Lung Cancer: Epithelial Mesenchymal Transition (EMT), the Missing Link? EBioMedicine 2015;2:1578-9.

40. Mahmood MQ, Ward C, Muller HK, et al. Epithelial mesenchymal transition (EMT) and non-small cell lung cancer (NSCLC): a mutual association with airway disease. Med Oncol 2017;34:45.

41. Sohal SS, Soltani A, Reid D, et al. A randomized controlled trial of inhaled corticosteroids (ICS) on markers of epithelial-mesenchymal transition (EMT) in large airway samples in COPD: an exploratory proof of concept study. Int J Chron Obstruct Pulmon Dis 2014;9:533-42.

42. Vestbo J, Hurd SS, Agusti AG, et al. Global strategy for the diagnosis, management, and prevention of chronic obstructive pulmonary disease: GOLD executive summary. Am J Respir Crit Care Med 2013;187:347-65.

43. Gomes M, Teixeira AL, Coelho A, et al. The role of inflammation in lung cancer. Adv Exp Med Biol 2014;816:1-23.

44. Van den Eeden SK, Friedman GD. Forced expiratory volume (1 second) and lung cancer incidence and mortality. Epidemiology 1992;3:253-7.

45. Greenberg AK, Hu J, Basu S, et al. Glucocorticoids inhibit lung cancer cell growth through both the extracellular signal-related kinase pathway and cell cycle regulators. Am J Respir Cell Mol Biol 2002;27:320-8.

46. Liang H, Kowalczyk P, Junco JJ, et al. Differential effects on lung cancer cell proliferation by agonists of glucocorticoid and PPAR $\alpha$ receptors. Molecular carcinogenesis 2014;53:753-63.

47. Murphy SH, Suzuki K, Downes M, et al. Tumor suppressor protein (p)53, is a regulator of NF-kappaB repression by the glucocorticoid receptor. Proc Natl Acad Sci U S A 2011;108:17117-22.

48. Gibbons DL, Byers LA, Kurie JM. Smoking, p53 mutation, and lung cancer. Mol Cancer Res 2014;12:3-13.

49. Yao R, Wang Y, Lemon WJ, et al. Budesonide exerts its chemopreventive efficacy during mouse lung tumorigenesis by modulating gene expressions. Oncogene 2004;23:7746-52.

50. Ordonez-Mena JM, Schottker B, Mons U, et al. Quantification of the smoking-associated cancer risk with rate advancement periods: meta-analysis of individual participant data from cohorts of the CHANCES consortium. BMC Med 2016;14:62.

51. Liu JC, Yang TY, Hsu YP, et al. Statins dose-dependently exert a chemopreventive effect against lung cancer 
in COPD patients: a population-based cohort study. Oncotarget 2016;7:59618-29.

52. Stapelfeld C, Dammann C, Maser E. Sex-specificity in lung cancer risk. Int J Cancer 2020;146:2376-82.

Cite this article as: Ge F, Feng Y, Huo Z, Li C, Wang R, Wen Y, Gao S, Peng H, Wu X, Liang H, Cheng B, Zhong R, He J, Liang W. Inhaled corticosteroids and risk of lung cancer among chronic obstructive pulmonary disease patients: a comprehensive analysis of nine prospective cohorts. Transl Lung Cancer Res 2021;10(3):1266-1276. doi: 10.21037/tlcr-20-1126
53. Carder M, Darnton A, Gittins M, et al. Chest physicianreported, work-related, long-latency respiratory disease in Great Britain. Eur Respir J 2017;50:1700961. 